\title{
Strategic Direction for the Development of SMEs - Based on the Successful Experience of POP MART
}

\author{
Ruiyuan Qi ${ }^{1, *}$
}

\author{
${ }^{1}$ Business School, The university of Sydney, Sydney, Australia, NSW 2006 \\ *Corresponding author.Email: ruqi7858@uni.sydney.edu.au
}

\begin{abstract}
At present, the lifestyle toy industry has shown great development potential in both domestic and international markets. With the introduction of blind box products into China, the market of blind box products in China has rapidly grown to a ten million market. Since its establishment 11 years ago, POP MART has transformed itself from a small toy collection store to an IP brand that mainly develops its own products. With the concept of "blind box", POP MART has become the most famous toy company in China. The emergence of POP MART satisfies the young generation's exploration of the unknown and love of art. It weakens the distance of "art" and pulls it into the life of the younger generation. POPMART's blind box products will also give more anxious young people a mind to relax.

Thus, this article aims to analyze the risks and disadvantages of small and medium-sized lifestyle toy companies based on the successful experience of POP MART in the context of the growing lifestyle toy market, to put forward suggestions for the development of small and medium-sized toy companies. Besides, SWOT model is used to analyze the strengths, weaknesses, opportunity, threats of SMEs in lifestyle toy industry.

Finally, it concludes that the emergence of the blind box and the gradual transformation of its business model are the keys to POP MART's success. In addition, SMEs in the lifestyle toy industry have problems such as low profit, financing difficulties, insufficient research and innovation ability, great competitive pressure, increased cost, and brain drain, and there are also opportunities for them to learn from experience, facilitate talent discovery, government policy support and excellent economic environment. Therefore, lifestyle toy SMEs should pay attention to increase the company's innovation capacity, subdivide customer groups, enhance targeted and competitiveness, constantly update products to increase competitiveness, and focus on improving the visibility of the company.
\end{abstract}

Keywords : lifestyle toy, SMEs, development strategy, business model, blind box, SWOT analysis

\section{INTRODUCTION}

lifestyle toys, also known as art toys, are different from children's toys. lifestyle toys integrate the concept of designers and artists into toy sculpture. Sales of lifestyle toys in the domestic market are climbing year by year, and some of the products have been sold overseas. At the same time, with the popularity of the concept of "blind box" in China, the lifestyle toy industry is growing rapidly. "Blind box" refers to a cardboard box containing different dolls without any style warning, so that the consumer does not know the style of the toys until they open it[3]. The growth of the "blind box" is closely related to the Intellectual property gaming industry.
According to existing surveys, independent designers and gaming studios began to appear in China in 2005, in 2010, POP MART and other cultural trend companies began to standardize the gaming market. Subsequently, the launch of 52Toys and other platforms further drove the growth of Intellectual property lifestyle toys in the Chinese market [4]. Some small and medium-sized lifestyle toy companies have followed the lead of POP MART and started to launch blind box toys. The retail market size of Lifestyle toys in China has grown from 135.6 billion yuan in 2013 to 324.1 billion yuan in 2018[2]. In addition, some studies have analyzed the blind box economy, consumers' enthusiasm for fashionable toys, and the promotion of traditional culture in the form of blind boxes. This paper aims to study the business strategies of SMEs, and starting from the reasons for the success of POP 
MART, then use SWOT to analyze the advantages, disadvantages, opportunities, and threats of SMEs in the lifestyle toy industry, and finally put forward ideas and suggestions for the future development strategies of SMEs.

\section{FACTORS OF POP MART'S SUCCESS}

\subsection{Blind box products of POP MART}

"Blind box" is a trend of toys, loved by consumers. POP MART is a pioneer in exploring the market with blind boxes. It combines the form of blind boxes with knowledge products and achieves a very significant effect. Since the blind box appeared on the market, the scale of the retail market for fad games in China has increased dramatically. POP MART also outsold other well-known toy companies such as Lego during the 2019 Singles Day sales festival, thanks to blind box sales [4]. In addition, exclusive intellectual property, dolls based on popular cartoon characters, and low selling prices make POP MART's blind box products more competitive. Therefore, POPMART's success is closely related to the emergence of "blind spots", but also has a little bit to do with its own development.

\subsection{Evolution of POPMART's business model (2010-2021)}

The business model canvas can be subdivided into a value proposition, key businesses, key partners, core resources, customer relationships, channel access, customer segmentation, cost structure, and revenue sources[5]. Enterprises usually build their unique business models through the opportunities created by the uncertain environment to gain competitive advantage and excellent performance.

The important partners of POP MART have changed from the original fashion product suppliers to IP creation teams and toy manufacturers; Key businesses are also shifting from channel agents to IP operators. The main business of the company is to discover more artists, launch self-owned fashion toys, and strengthen the brand's uniqueness[6].

The core resources have changed from the quality and richness of the original products to the ability to signing a team of designers, IP incubation, and operation. The sales channels have changed from the original offline stores to online flagship stores, WeChat mini-programs, second-hand trading platforms, trendy toys exhibitions, and offline stores. Sales channels have become very broad, driving much of the growth in sales. The relationship between the company and customers has also changed from a simple supply and demand related to the operation of a community of fans and the promotion of a popular play culture within the community. POP MART gradually focuses on creating its own branded products, constantly innovating and introducing products that consumers love, which makes its brand image more competitive. In addition, a wide range of sales channels provide consumers with opportunities and convenience to know and buy popular games, and some fan community activities also provide customers with some price concessions. In addition, the company has also subdivided the customer types, dividing a wide range of young people into different categories of fad fans, which makes the company's product design more targeted and increases the innovation efficiency of POP MART.

In the end, the cost changed from the purchase cost of the product to the design team's salary and operation and management expenses, and the revenue source changed from the agency fee income and the price difference of the goods to the sales income of the fad game and the income from IP licensing, development, operation and cooperation[6]. That's the majority of the company's revenue and expenses, and it's because of this change that POP MART has found the right designers and the right brands to partner with, transforming it from a small toy store that resells other people's designs into a business with independent brand influence.

\section{SWOT analysis of SMEs}

SWOT analysis is a comprehensive and systematic analysis of the company's internal strengths and weaknesses, external opportunities and challenges, management standards and guidelines, etc., based on the short-term and long-term goals of the company. In this way, when any enterprise is developing its development strategy, it will formulate its operation and development strategy through the basic situation of advantages and opportunities. Therefore, SWOT analysis is a basic enterprise strategy analysis method.

\subsection{The internal strengths}

Firstly, POP MART has opened up a development path for lifestyle toy enterprises. Learning from the development of POP MART, SMEs in lifestyle toy industry can save development costs and avoid some risks. In addition, most lifestyle toy SMEs are established in central cities, which provides convenient conditions for the introduction of talents. POP MART spends a lot of money on finding and training designers, which is at the heart of its ability to design and produce distinctive products, so talented designers are crucial for trendy businesses. Companies can introduce excellent design talents from many design schools and fashionable exhibitions. The top 10 famous design schools in China are all located in Beijing, Shanghai, and central cities in the province. 


\subsection{The internal weakness}

First of all, individual goods have lower profits. Since the price of most popular products is low, most products like POP MART sell for only $\$ 59$, so it's hard to make a profit with fewer sales[1]. The income of SMEs will be limited in the early stage of development.

In addition, SMEs have difficulty in financing. Capital is the most basic factor in the development and operation of any enterprise. Small and medium-sized businesses lack competitive advantages compared to big companies like POP MART, so it is difficult for SMEs to obtain the funds they need. Morever, the quantity and price of loans for SMEs in the credit market are not ideal.[9]

Finally, SMEs have a low ability of research and development and technological innovation. This is mainly because most small and medium-sized enterprises have a short development time and less capital accumulation. For POP MART, it has taken several years to optimize and reform its innovation system since its inception before it finally acquired the ability to independently design and create original products.

\subsection{External opportunity}

\subsubsection{The political environment}

With the continuous improvement of Chinese people's living standards and the increasing demand for material culture, the Chinese government has realized the importance of developing cultural and creative industries [7]. China has adjusted its layout for the development of cultural and creative industries. For example, Beijing proposes to make cultural and creative industries a pillar industry of the capital's economy. China has also adopted some specific policies to support the development of cultural and creative industries [3]. In terms of financial subsidies, the government has set up a special fund for cultural and creative industries. In terms of tax incentives, the government provides some tax relief for cultural and creative industries. Moreover, Chinese financial department and tax bureau have taken a series of measures to reduce the burden of small and medium-sized lifestyle toy enterprises, providing them with extremely favorable policy support and guarantee.

\subsubsection{The economic environment}

At present, under the background of economic globalization, it has provided a good opportunity for SMEs in lifestyle toy industry to enter the international market. At the same time, China's relatively stable economic development environment, the upgrading of consumption structure, and the growth of foreign trade have provided opportunities for SMEs in lifestyle toy industry to diversify their development [7]. In addition, China's financial system provides powerful loan guarantee services for SMEs, which reduces their financing costs and alleviates the problem of short-term capital shortage for SMEs [9]. Financial institutions have also provided support and assistance to SMEs to solve their medium - and long-term financing problems[9]. Therefore, China's economic environment provides a favorable opportunity for SMEs in lifestyle toy industry.

\subsection{External threats}

The first is that the competition for lifestyle toys is increasing, and some new lifestyle toy companies are entering the market. On the second-hand trading platform, in addition to the high trading volume of Molly, the blind box product of POP MART, the blind box products of other IP are also highly popular [2]. In addition, some lifestyle toy enterprises achieve good performance, investors will increase, which will lead to more and more production of trendy play products. Therefore, in the trendy toy market, the competition among SMEs will become more and more fierce, which poses a serious threat to the development of enterprises.

And then the lifestyle toy SMEs are facing the risk of brain drain. Compared with large enterprises, which have higher efficiency, better welfare, and bright prospects, SMEs are less attractive to talents [9].

Also, in the lifestyle toy industry environment, enterprises need to develop new lifestyle toys, strengthen their own brands' value, which lead to an increase in enterprise costs. Companies like POP MART that have grown up with slightly higher costs are still a concern. In 2020, POP MART's costs increased by $54.97 \%$ year on year due to intellectual property design and licensing [10]. Since the discovery of artists and the innovation of brand products require a large amount of capital, and most SMEs are in the primary stage of development, the company income is small, therefore, high cost has become a great threat to them.

\section{SUGGESTIONS FOR THE DEVELOPMENT STRATEGY OF SMES}

\subsection{Increase the company's innovation capacity}

The company needs to spend major funds on the creation and operation of intellectual property and attract famous intellectual property suppliers to establish cooperation. For example, companies can provide funds to train artists to lay the foundation for good work. At the same time, the company can form the authorization of its own intellectual property, such as the authorization of co-branded goods and films. 
Finally, SMEs can create the intellectual property of Traditional Chinese culture, design fashionable toys with Chinese characteristics. These measures have greatly increased the company's design and innovation capabilities.

\subsection{Subdivide customer groups, enhance targeted and competitiveness}

First of all, enterprises can obtain consumer data in the form of questionnaires, so as to know the mainstream aesthetic trend and the demand of minorities, which has a great guiding effect on designers' design direction. In addition, the segmentation of customer groups according to different aesthetic categories and needs of consumers can better design and produce products that consumers like. Moreover, companies need to pay attention not only to consumers in central cities but also to consumers in small and medium-sized cities and remote areas, and produce products with different prices to meet the needs of these consumers [8]. By classifying products and designing and pricing them according to different types of consumer needs, they can be sought after by more customers and increase their competitiveness in the same type of products.

\subsection{Constantly update products to increase competitiveness}

In today's rapid economic development, the public's aesthetic preference is also changing, small and medium-sized enterprises need to enhance their ability to adapt to market changes, brave to meet unknown challenges; In addition, the company needs to find out one of its commercial factors with advantages, and make efforts to give play to this advantage to form its own unique competitiveness. As for the commercial factors with relative disadvantages, the company also needs to timely adjust and innovate.

\subsection{Focus on improving the visibility of the company and attracting talents to join}

First of all, the company should pay attention to the basic publicity activities such as advertising and publicity in WeChat public account [8]. Secondly, we should participate in more international and domestic art exhibitions to gain a good reputation in the industry. In this way, more excellent designers will be willing to cooperate with the company, and reduce the risk of brain drain. In addition, the company needs to establish a fan community and implement a membership system in the community to attract more customers. Meanwhile, it also needs to hold regular activities such as design competitions in the community to maintain fans' enthusiasm for the brand and products.

\section{CONCLUSION}

In general, POP MART has achieved success through the marketing philosophy of blind box products and an increasingly optimized business model. By analyzing the transformation process of its business model, it is found that lifestyle toy SMEs can learn from the existing excellent aspects, such as paying attention to self-created intellectual property, strengthening cooperation with designers and other brands. Nowadays, SMEs in the lifestyle toy industry face challenges and threats such as low profit rate of individual goods, financing difficulties, insufficient $R \& D$ and innovation ability, loss of human resources, and rising costs. Finally, it is concluded that lifestyle toy SMEs should pay attention to increase the company's innovation capacity, subdivide customer groups, enhance targeted and competitiveness, constantly update products to increase competitiveness, and focus on improving the visibility of the company.

In addition, the analysis method of the successful experience of POP MART in this paper has drawbacks. The method is a little simple with a single direction. In the future, we can explore the reasons for the success of POP MART from more aspects, such as consumer psychology and the popularity of blind boxes. Future research can focus on exploring how lifestyle toy industry SMEs go forward in the long term and how they choose partners to cooperate with other industries to produce diverse trendy products.

\section{REFERENCES}

[1] Pop Mart Action figure art toys blindbox collectible chinese pop brand. popmart global. (2021). Retrieved 23 August 2021, from https://global.popmart.com/.

[2] POP MART: The Blind box economy \& designer toy market in China. Daxueconsulting.com. (2021). Retrieved 23 August 2021, from https://daxueconsulting.com/pop-mart-designer-toy -market-in-china/.

[3] Xu, W. (2020). To popularize traditional culture strategy research in the form of "blind box". Journal Of Tongling University, pp. 91-92.

[4] Su, Q. (2020). Tide plays the secret of the first, bubble Matt's lucrative business. View Of Finance And Economics, 76-79. Retrieved 23 August 2021, from http://www.cnki.net.

[5] (2021). Retrieved 23 August 2021, from https://www.semanticscholar.org/paper/BusinessModels\%3A-Origin\%2C-Development-and-Future -Wirtz-Pistoia/2cf1d71621bbd45c0c662692b72b90 2a309d226e. 
[6] Wang, C., \& Liu, Y. (2021). Research on driving factors of business evolution -- Exploration of The business model of POPMART. Financial Management Research.

[7] Jiang, Y., Yang, X., \& Li, M. (2019). China's cultural and creative industry policy effect and regional heterogeneity. Journal Of Management, 32(5), 9-12.
[8] Li, Y. (2020). Research on the development problems and Countermeasures of China's fashion toy industry. Contemporary Economic, (7), 82-84.

[9] Ye, J. (2014). Development strategy of small and medium-sized enterprises in Anhui Province (Postgraduate). Anhui University of Finance and Economics.

[10] POP MART's four worries. (2020), 15. Retrieved 1 September 2021. 